\title{
Knowledge and attitude towards mother to child transmission of HIV and it's prevention among post natal mothers in Tikur Anbessa and Zewditu Memorial Hospitals, Addis Ababa
}

\author{
Solomie Jebessa ${ }^{1}$, Telahun Teka ${ }^{2}$
}

\begin{abstract}
Background: HIV/AIDS is currently a major public health problem in Ethiopia and mother to child transmission (MTCT) is responsible for $90 \%$ of childhood HIV infections. The transmission of HIV from infected mothers to babies could occur during antenatal period, as well as during delivery and breastfeeding (postnatal period). Since breastfeeding is essential for child survival, it is also necessary to assess mothers' knowledge and attitude towards HIV transmission and its prevention during breastfeeding.

Objectives: This study attempts to assess mothers' knowledge of MTCT of HIV including breastfeeding, in two government hospitals in Addis Ababa. It also describes mothers' attitudes towards voluntary counseling and testing (VCT) services.

Methods: A cross sectional, descriptive study was conducted to assess knowledge and attitude towards MTCT and its' preventive methods on postnatal mothers who delivered at Tikur Anbessa and Zewditu Memorial Hospitals, Addis Ababa, from January to March 2004. A structured, pre-tested questionnaire was used for data collection.

Results: A total of 384 mothers were interviewed 78.4\% of whom were from Addis Ababa. 87.0\% were aged between 16-30 years. Of these mothers $54.9 \%$ were primipara, $89.9 \%$ were married, and $84.6 \%$ were Christians. Amhara (44.5\%), Oromo (26.3\%), Gurage (17.2\%), and Tigre (7.0\%) were the major ethnic groups in the study population. All the 384 respondents had heard about HIV/AIDS of which, $82.3 \%$ mentioned the major routes of transmission and $89.8 \%$ knew that that HIV could be transmitted from an infected mother to her baby. Most of the respondents $(76.8 \%)$ knew that MTCT of HIV is preventable, $64.6 \%$ knew the protective effect of prophylactic anti-retroviral drugs, $37.1 \%$ knew that abstinence from breastfeeding can prevent MTCT, $10.4 \%$ knew elective caesarean section $(\mathrm{C} / \mathrm{S})$ as a preventive method and $6.9 \%$ stated that protection of the mother from HIV is the same as protecting her baby. Those mothers who were from Addis Ababa, and whose educational level was secondary and above were found to be more knowledgeable about MTCT and PMTCT. Three hundred seventeen $(82.6 \%)$ of the mothers knew what VCT meant and $76.8 \%$ of them have positive attitudes to wards VCT. $69.3 \%$ of the mother indicated that mothers should be tested before breastfeeding and $67.4 \%$ agreed to have VCT before breastfeeding their new babies. $60.2 \%$ planned to have VCT before their next pregnancy.

Conclusion: This study showed that most mothers in this study knew that HIV could be transmitted from mother to child and that it can be prevented. A majority are of the opinion that VCT can be a preventive strategy and most of them have the intention to have counseling and testing before the next pregnancy. Hence well-organized VCT centers and PMTCT programs should be established to halt the epidemic from affecting the next generation. [Ethiop.J.Health Dev. 2005;19(3):211-218]
\end{abstract}

\section{Introduction}

A global overview of the HIV/AIDS epidemic indicates that 42 million people are at present living with HIV/AIDS, of which 19.2 million are women and 3.2 million are children under 15 years of age. (1). According to the Ethiopian Federal Ministry of Health (2002) 2.2 million people are living with AIDS in Ethiopia, of which, 1.1 million are women. The number of children $<15$ years of age living with HIV/AIDS was 200,000 (2).

HIV Infections and AIDS are threatening the gains made in child survival through the use of child immunization, improved case management of diarrhoeal diseases and acute respiratory infections (3). An estimated 600,000 new borns world wide are infected through mother to child transmission each year (>1600 new born infected each day) and $90 \%$ of them live in sub-Saharan Africa $(4,5)$.

Rates of transmission of HIV from mothers to children have varied in different parts of the world. Most studies in the US and Europe have documented transmission rates in untreated women to be between $12-30 \%$. In contrast, transmission rates in Africa and Haiti were reported to be higher $(25 \%$ $52 \%)(6)$.

Vertical transmission of HIV can occur before (intrauterine), during (intra-partum), or after delivery (through breast-feeding). It is generally accepted that $30-40 \%$ of

\footnotetext{
${ }^{1}$ Department of Pediatrics and Child Health, Faculty of Medicine, Addis Ababa University, Tel. 09-407063, Addis Ababa, Ethiopia; ${ }^{2}$ Department of Pediatrics and Child Health, Faculty of Medicine, Addis Ababa University, Tel.09254270, Addis Ababa, Ethiopia
} 
newborns are infected in utero as evidenced by positive viral culture or polymerase chain reaction (PCR) tests within the first week of life (6).The mechanisms of transmission appear to be exposure to infected blood and cervico-vaginal secretions in the birth canal where HIV is found in high titers during late gestation and during delivery. Breastfeeding is also an important transmission route in developing countries. (6)

The World Health Organization (WHO) promotes a threepronged approach to reduce MTCT of HIV. Therefore: the prevention of new infections in parents, avoiding unwanted pregnancies in HIV infected women (primary preventions) and preventing transmission of HIV from an infected mother to her infant (secondary preventions) (3).

Nowadays, with a combination of anti-retroviral prophylaxis, elective caesarean section and by abstinence from breastfeeding it is possible to reduce MTCT of HIV to $<2 \%$ in developed countries. As this is not still possible in resource-poor countries, primary prevention is considered as the most important way to decrease MTCT of HIV. A well functioning, appropriate and accessible VCT service is a prerequisite for a successful MTCT prevention program (5). Mothers should be aware about HIV/AIDS and its routes of transmission to children and they should be motivated to recognize their sero-status and be advised on primary and secondary preventive measures.

\section{Methods}

A cross-sectional study was conducted on postnatal mothers in the labor and maternity wards of Tikur Anbessa and Zewditu Memorial Hospitals from January to March, 2004. All post natal mothers were studied with the exception of mothers with still births, preterm, and congenital malformations. And those mothers who were in NIGAT project were excluded to avoid bias since they already have good knowledge on MTCT \& PMTCT.

The sample size was calculated using the formula for cross-sectional survey. $Z^{2} \alpha / 2$ is a precision to an acceptable approximation of the population and it was taken to be $95 \%\left(Z^{2} \alpha / 2=1.96\right): P$ is the proportion of mothers with knowledge about MTCT of HIV. Since there are no studies on mothers regarding this topic, $\mathrm{p}$ is used as $50 \%$ to achieve the maximum sample size. D is the absolute precision, and is taken as 0.05 .

Thus $\left.\mathrm{n}=\frac{(1.96)^{2} 0.5(1-0.5)}{(0.05)^{2}}\right]$

The sample size was calculated to be 384 using the above formula. The questionnaire was prepared and translated in to Amharic and was later pretested. The principal investigator trained two staff nurses to collect data according to the prepared questionnaires. Mothers were requested to give their verbal consents before the interview. All of them were requested to participate voluntarily and were reassured that the information they provide will be kept confidential. The general information will be used for local policy issues. Variables used included sociodemographic characteristics and factors related to knowledge and attitudes regarding MTCT, PMTCT (Prevention of Mother to Child Transmission), VCT and breastfeeding.

Data were entered into a computer using SPSS statistical software. Analysis including frequencies, percentages, odds ratios and bivariate analyses were used for reporting the findings.

\section{Results}

A total of 384 mothers participated in the study, $78.5 \%$ of whom were from Addis Ababa while the rest were from different areas of the country. The mean $( \pm \mathrm{SD})$ age of the mothers was $25.4( \pm 5.08)$, and $54.9 \%$ were primipara. $89.8 \%$ were married, and $84.6 \%$ were Christian.

Amhara, Oromo, Gurage and Tigre constituted 44.5\%, $26.3 \%, 17.2 \%$ and $7.0 \%$ of their nationalities respectively. Fifty three percent of the mothers had attended secondary grade levels, $70.1 \%$ were housewives and $55.6 \%$ earn less than 300 ETB per month (Table 1).

All the 384 respondents reported to have heard about the disease HIV/AIDS, $82.3 \%$ mentioned all the major routes, of transmission $12.2 \%$ mentioned two routes and $4.2 \%$ mentioned only one route, the rest $1.3 \%$ did not know. Three hundred forty five mothers $(89.9 \%)$ knew that HIV can be transmitted from a mother to her child, of this $99.4 \%$ knew at least one period of transmission, while $55.4 \%$ mentioned all the periods which are: during pregnancy, delivery and breast feeding.

As to the period for the highest rate of HIV transmission, $149(43.2 \%)$ mothers responded that it occurs during labor, $32.2 \%$ said it occurs during pregnancy (intrauterine) and $22.9 \%$ said that it occurs while breast feeding the rest answered combinations of these.

Regarding mothers' knowledge of the range of percentage of MTCT, $243(70.4 \%)$ mothers said that they know the chance of transmission: 21 of them said that it is below $25 \%, 117$ of them said that it is between 25 and $50 \%$ and 105 of them said that it is above $50 \%$. One hundred two $(29.6 \%)$ of the mothers said they did not know.

As could be seen from Table 2, those mothers who were above twenty years of age were more knowledgeable about MTCT of HIV than those who were younger; and the relationship was statistically significant for those who were 21-25 years, and 31 and above years. Likewise, the educational status of mothers has statistically significant association with their knowledge, in that those who have attended secondary school and above were found to be more knowledgeable than those who have no formal education. 
Table 1: Socio-demographic characteristics of mothers $(n=384)$. Addis Ababa, Jan. - March 2004

\begin{tabular}{|c|c|c|}
\hline Variables & Frequency & Percent \\
\hline \multicolumn{3}{|l|}{ Place of residence of mothers } \\
\hline Addis Ababa & 301 & 78.4 \\
\hline Outside Addis Ababa & 83 & 21.6 \\
\hline \multicolumn{3}{|l|}{ Age of mothers [Mean $( \pm S D)=25.41( \pm 5.08)$ ] } \\
\hline $16-20$ & 86 & 22.4 \\
\hline $21-25$ & 119 & 31.0 \\
\hline $26-30$ & 129 & 33.6 \\
\hline $31-35$ & 36 & 9.4 \\
\hline $36-40$ & 14 & 3.6 \\
\hline \multicolumn{3}{|l|}{ Parity of mothers } \\
\hline Grand multipara $(>5)$ & 8 & 2.1 \\
\hline Multipara $(2-5)$ & 165 & 43.0 \\
\hline Primipara & 211 & 54.9 \\
\hline \multicolumn{3}{|l|}{ Marital status } \\
\hline Married & 345 & 89.8 \\
\hline Single & 33 & 8.6 \\
\hline Divorced & 5 & 1.3 \\
\hline Widowed & 1 & 0.3 \\
\hline \multicolumn{3}{|l|}{ Religion } \\
\hline Christian & 325 & 84.6 \\
\hline Moslem & 59 & 15.4 \\
\hline \multicolumn{3}{|l|}{ Ethnicity } \\
\hline Amhara & 171 & 44.5 \\
\hline Oromo & 101 & 26.3 \\
\hline Gurage & 66 & 17.2 \\
\hline Tigre & 27 & 7.0 \\
\hline Others* & 12 & 3.1 \\
\hline Didn't mention & 3 & 1.8 \\
\hline \multicolumn{3}{|l|}{ Educational status } \\
\hline No formal education & 76 & 19.8 \\
\hline Primary (grades 1-6) & 75 & 19.5 \\
\hline Secondary (grades 7-12) & 204 & 53.1 \\
\hline Post secondary (12+) & 29 & 7.6 \\
\hline \multicolumn{3}{|l|}{ Occupation } \\
\hline Housewife & 269 & 70.1 \\
\hline Government employed & 53 & 13.8 \\
\hline Private & 33 & 8.6 \\
\hline Merchant & 14 & 3.6 \\
\hline Other** & 15 & 3.9 \\
\hline \multicolumn{3}{|l|}{ Household monthly income } \\
\hline$<100$ ETB per month & 124 & 32.3 \\
\hline 101-300 ETB per month & 97 & 25.3 \\
\hline 301-500 ETB per month & 51 & 13.3 \\
\hline$>500$ ETB per month & 81 & 21.1 \\
\hline Did not want to mention their income & 31 & 8.1 \\
\hline
\end{tabular}

* Other ethnic groups: Silte (3), Somali (3). Hadia (2), Adere (1), Gamo (1), Kembatta (1), and Worji (1)

** Other occupation: housemaid (4), street girl (3), student (2), peasant (2), beggar (1), daily laborer (1), family dependant (1) and jobless (1).

Conversely, mothers' place of residence, marital status, religious affiliation, ethnicity, occupational status, average monthly income and parity did not have significant association with their knowledge on MTCT of HIV.

Most of the respondents (76.8\%) know that MTCT of HIV is preventable, while $15.7 \%$ said that it is not preventable and $7.5 \%$ said they did not know. On the other hand, $64.6 \%$ knew the protective effect of prophylactic antiretrovirals, $37.1 \%$ knew that abstinence of breast feeding can prevent MTCT of HIV, $10.4 \%$ knew that elective CIS delivery can prevent and $6.9 \%$ of them said that protecting a mother from HIV also protects her baby. 
Table 2: Knowledge of mothers about MTCT of HIV vs. socio-demographic variables ( $n=345)$. Addis Ababa. January - March 2004

\begin{tabular}{|c|c|c|c|c|}
\hline \multirow{2}{*}{\multicolumn{2}{|c|}{ Socio-demographic variables }} & \multicolumn{3}{|c|}{ Knowledge on MTCT of HIV } \\
\hline & & \multirow{2}{*}{\begin{tabular}{|l|} 
Yes \\
274
\end{tabular}} & \multirow{2}{*}{$\begin{array}{r}\text { No } \\
27\end{array}$} & \multirow{2}{*}{$\begin{array}{l}\text { OR }(95 \% \mathrm{Cl}) \\
1.00\end{array}$} \\
\hline Place of residence & Addis Ababa & & & \\
\hline & Outside Addis Ababa & 71 & 12 & $0.58(0.27,1.33)$ \\
\hline \multirow[t]{4}{*}{ Age of mothers } & $16-20$ & 68 & 18 & 1.00 \\
\hline & $21-25$ & 115 & 4 & $7.61(2.35,31.89)$ \\
\hline & $26-30$ & 115 & 14 & $2.17(0.95,5.04)$ \\
\hline & 31 and above & 47 & 3 & $4.15(1.11,23.09)$ \\
\hline \multirow[t]{2}{*}{ Martial status } & Married & 313 & 32 & 1.00 \\
\hline & Single/widowed/divorced & 32 & 7 & $0.47(0.18,1.36)$ \\
\hline \multirow[t]{2}{*}{ Religion } & Christian & 293 & 32 & 1.00 \\
\hline & Moslem & 52 & 7 & $0.81(0.33,2.30)$ \\
\hline \multirow[t]{4}{*}{ Ethnicity } & Amhara & 157 & 14 & 1.00 \\
\hline & Oromo & 89 & 12 & $0.66(0.27,1.64)$ \\
\hline & Gurage & 55 & 11 & $0.45(0.18,1.16)$ \\
\hline & Others & 41 & 2 & $1.83(0.39,17.17)$ \\
\hline \multirow[t]{3}{*}{ Educational status } & No formal education & 61 & 15 & 1.00 \\
\hline & Primary (grades 1-6) & 63 & 12 & $1.29(0.52,3.28)$ \\
\hline & Secondary and above & 221 & 12 & $4.53(1.86,11.14)$ \\
\hline \multirow[t]{4}{*}{ Occupation } & Housewife & 242 & 27 & 1.00 \\
\hline & Government employed & 49 & 4 & $1.37(0.45,5.61)$ \\
\hline & Private & 30 & 3 & $1.12(0.31,6.09)$ \\
\hline & Other & 24 & 5 & $0.54(0.18,1.95)$ \\
\hline \multirow{4}{*}{$\begin{array}{l}\text { Household monthly } \\
\text { income }\end{array}$} & $<100$ ETB & 113 & 11 & 1.00 \\
\hline & 101-300 ЕTВ & 87 & 10 & $0.85(0.31,2.34)$ \\
\hline & 301-500 ЕTB & 47 & 4 & $1.14(0.32,5.17)$ \\
\hline & >500 ETB & 76 & 5 & $1.48(0.45,5.65)$ \\
\hline \multirow[t]{3}{*}{ Parity of mothers } & Primipara & 191 & 20 & 1.00 \\
\hline & Multipara & 148 & 17 & $0.91(0.44,1.93)$ \\
\hline & Grand multipara & 6 & 2 & $0.31(0.05,3.41)$ \\
\hline
\end{tabular}

Those who live outside Addis Ababa had significantly less knowledge about PMTCT than those who came from Addis Ababa, OR $(95 \%$ CI $)=0.38(0.19,0.77)$. In addition, the educational level of mothers also had a statistically significant association with their knowledge about PMTCT, in that those who were above secondary level had good knowledge as compared with those who have no formal education. Mothers who have many children ( $>5$ children) were also found to be less knowledgeable about PMTCT than those that had lesser numbers of children. On the contrary, mothers' age, marital status, religion, occupation, monthly income and ethnicity did not affect their knowledge in this regard (Table 3).

Three hundred and seventeen $(82.6 \%)$ of the mothers know what voluntary counseling and testing means, and $295(76.8 \%)$ of them have the opinion that every mother should have VCT to prevent MTCT of HIV, while $82.3 \%$ agreed to have VCT.The reasons why majority of the mothers wanted to have the test was to know their serologic status. $27(7 \%)$ rejected VCT services and the reason of the majority was fear of the test results. Mothers who live outside Addis Ababa were found to have less knowledge about VCT as compared to residents in Addis Ababa, which was statistically significant [OR $(95 \% \mathrm{CI})=0.38(0.21,0.70)]$. Mothers who were in the age group between 21 to 30 years were found to have better awareness about VCT on HIV than those aged less than 20 years. Here again, those mothers whose educational levels were secondary and above had better knowledge VCT. Single, widowed or divorced mothers were also found to have less knowledge about VCT than married ones [OR $(95 \% \mathrm{CI})=00.43(0.20,0.99)]$. Mothers who had five children and above were found to have significantly less knowledge than those with fewer children $[\mathrm{OR}(95 \% \mathrm{CI})=0.17(0.03,0.95)]$. Otherwise, religion, ethnicity, occupation and monthly income didn't show statistically significant association with their 
knowledge regarding VCT (Table 4).

A majority of the respondents $(69.3 \%)$ indicated that mothers should be tested before deciding to breast-feed, their infants, $21(5.5 \%)$ of the respondents felt that mothers must breastfeed whether tested or not, $15.4 \%$ of them said that a mother should be tested if she suspects to have HIV, $0.5 \%$ of them said that it is better to abstain breastfeeding whether tested or not and the rest $9.4 \%$ did not respond. Most of the mothers $(67.4 \%)$ wanted to have counseling and testing for HIV before they breastfeed, $8 \%$ wanted to breastfeed regardless of their being tested, and the rest $17.6 \%$ did not respond.

Table 3: Knowledge of mothers on the possibility of prevention of MTCT of HIV vs.

socio-demographic variables $(n=265)$. Addis Ababa, January - March 2004

Socio-demographic variables

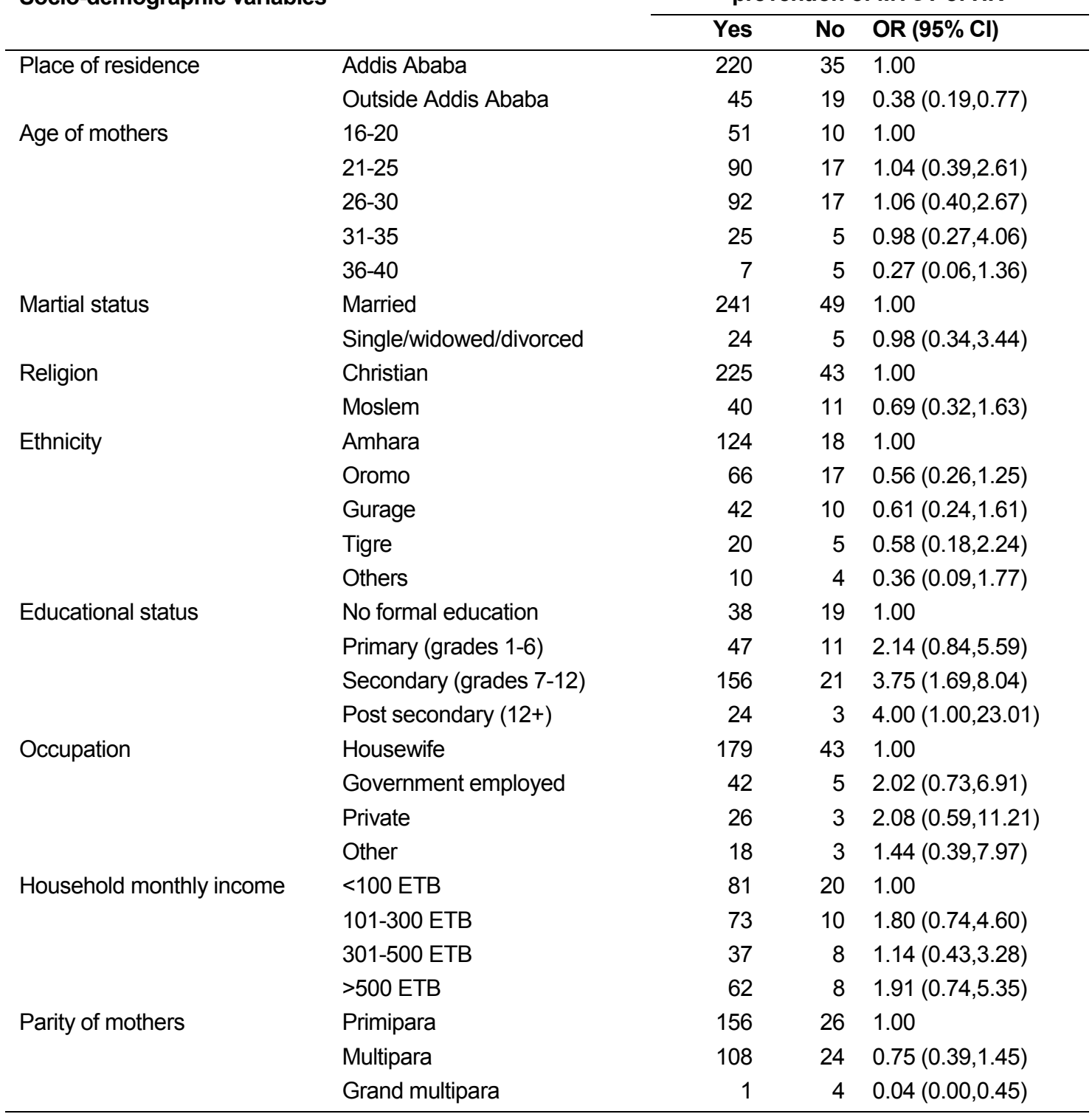

A closer look at the relationship of socio-demographic variables with attitudes of mothers about VCT in relation to breastfeeding showed no statistically significant association.Two hundred thirty two $(60.2 \%)$ respondents said that they would be tested before the next pregnancy, $15.4 \%$ could not decide, $10.7 \%$ did not want to have additional births $9.4 \%$ didn't respond and the rest gave different responses.

\section{Discussion}

There hundred sixty three (94.5\%) mothers in this study were able to mention the major routes of HIV transmission and this finding is consistent with the finding in Thailand in which, over $90 \%$ of each age and sex group studied answered correctly about the major conduits of HIV transmission (unprotected sex and sharing needles for I.V drug use) (7). 
Three hundred forty-five (89.8\%) mothers in this study know that HIV can be transmitted from an infected mother to her baby. This finding is also consistent with findings in Isiolo and Garissa districts of Kenya, where $84 \%$ and $83 \%$, knew MTCT of HIV respectively (8). In Thailand also, the proportions of those who correctly answered questions related to transmission during blood transfusion and perinatal routes including breast-feeding were very high for all age-sex categories (7).

In a previous study done in Tigray (1992), northern Ethiopia, among 60 patients with STDs and those in reproductive age groups (15-45 yr.), one-third of whom were women, awareness of the existence of HIV/AIDS was found to be $98.3 \%$, but only $8.3 \%$ knew the vertical transmission of HIV (9). In a study done in Bahirdar (1994), north-west Ethiopia among 1,115 out of school young people, $95.4 \%$ have heard about HIV from the mass media, as well as friends, and health institutions. Regarding the methods of HIV transmission, $92.5 \%$ mentioned sexual routes but only $21.7 \%$ of them mentioned MTCT of HIV (10). It is evident, therefore that awareness on MTCT has increased in the past decade in the country.

In this study, $243(70.4 \%)$ of the mothers gave the possible percentage of MTCT of HIV that they thought was correct; of these $117(48.1 \%)$ of the mothers said that the chance of transmission is $25-50 \%$; the other $105(43.2 \%)$ of them said that it was above $50 \%$; and $21(8.7 \%)$ of them said that it was below $25 \%$. This result was consistent with a study done in Rome, Italy among HIV infected mothers where, $13.8 \%$ of them thought that it was transmitted $100 \% ; 44.1 \%$ of them thought the chance of transmission is $50-80 \%$ and $10-50 \%$ of them thought that the risk was $5 \%$ (11).

\begin{tabular}{|c|c|c|c|c|}
\hline \multicolumn{2}{|c|}{ Socio-demographic variables } & \multicolumn{3}{|c|}{ Knowledge of VCT } \\
\hline & & \multirow{2}{*}{$\begin{array}{l}\text { Yes } \\
259\end{array}$} & \multirow{2}{*}{$\frac{\text { No }}{42}$} & \multirow{2}{*}{$\begin{array}{l}\text { Adj.OR (95\% Cl) } \\
1.00\end{array}$} \\
\hline Place of residence & Addis Ababa & & & \\
\hline & & 58 & 25 & $0.38(0.21,0.70)$ \\
\hline & Outside Addis Ababa & & & \\
\hline \multirow[t]{5}{*}{ Age of mothers } & $16-20$ & 60 & 26 & 1.00 \\
\hline & $21-25$ & 106 & 13 & $3.53(1.60,8.03)$ \\
\hline & $26-30$ & 109 & 20 & $2.36(1.16,4.85)$ \\
\hline & $31-35$ & 31 & 5 & $2.69(0.89,9.77)$ \\
\hline & $36-40$ & 11 & 3 & $1.59(0.37,9.56)$ \\
\hline \multirow[t]{2}{*}{ Martial status } & Married & 290 & 55 & 1.00 \\
\hline & Single/widowed/divorced & 27 & 12 & $0.43(0.20,0.99)$ \\
\hline \multirow[t]{2}{*}{ Religion } & Christian & 270 & 55 & 1.00 \\
\hline & Moslem & 47 & 12 & $0.80(0.39,1.76)$ \\
\hline \multirow[t]{5}{*}{ Ethnicity } & Amhara & 145 & 26 & 1.00 \\
\hline & Oromo & 80 & 21 & $0.68(0.35,1.37)$ \\
\hline & Gurage & 52 & 14 & $0.67(0.31,1.49)$ \\
\hline & Tigre & 26 & 1 & $4.66(0.70,198.38)$ \\
\hline & Others & 11 & 5 & $0.39(0.11,1.58)$ \\
\hline \multirow[t]{4}{*}{ Educational status } & No formal education & 49 & 27 & 1.00 \\
\hline & Primary (grades 1-6) & 55 & 20 & $1.52(0.72,3.23)$ \\
\hline & Secondary (grades 7-12) & 186 & 18 & $5.69(2.75,11.87)$ \\
\hline & Post secondary (12+) & 27 & 2 & $7.44(1.63,68.38)$ \\
\hline \multirow[t]{4}{*}{ Occupation } & Housewife & 221 & 48 & 1.00 \\
\hline & Government employed & 47 & 6 & $1.70(0.67,5.14)$ \\
\hline & Private & 30 & 3 & $2.17(0.63,11.55)$ \\
\hline & Other & 19 & 10 & $0.41(0.17,1.06)$ \\
\hline \multirow{4}{*}{$\begin{array}{l}\text { Household monthly } \\
\text { income }\end{array}$} & $<100$ ETB & 98 & 26 & 1.00 \\
\hline & 101-300 ETB & 85 & 12 & $1.88(0.85,4.34)$ \\
\hline & 301-500 ETB & 44 & 7 & $1.67(0.64,4.89)$ \\
\hline & $>500$ ETB & 73 & 8 & $2.42(0.99,6.53)$ \\
\hline \multirow[t]{3}{*}{ Parity of mothers } & Primipara & 181 & 30 & 1.00 \\
\hline & Multipara & 132 & 33 & $0.66(0.37,1.18)$ \\
\hline & Grand multipara & 4 & 4 & $0.17(0.03,0.95)$ \\
\hline
\end{tabular}


Most of the mothers (76.8\%) knew that MTCT of HIV could be prevented by protecting the mother from HIV, abstaining from breast feeding, cesarean section delivery and by giving prophylactic anti-retroviral drugs. About $45 \%$ of them mentioned one of the preventive methods, $19.7 \%$ mentioned two of the preventive methods and $10.4 \%$ of them mentioned three of the preventive methods of MTCT. Examining the details of their responses it was found that $37.1 \%$ of them knew that abstinence of breastfeeding can prevent MTCT. This finding is similar to the study results in Kenyan districts which showed $45 \%$ in Turkana, $32.8 \%$ in Kwale and $36 \%$ in Isiolo asserting that MTCT could be prevented by abstinence of breast feeding (8).

Three hundred and seventeen (82.6\%) of the mothers in the present study knew clearly what VCT means and $76.8 \%$ of mothers have the opinion that every mother should have VCT to prevent MTCT of HIV. Fifty one percent of health workers in the Kenyan districs of Kwale, $30 \%$ in Isiolo $41.9 \%$ in Garissa and $32.1 \%$ in Turkana reported that counseling for HIV was undertaken in their health facility regularly (12).

Most of the mothers (69.3\%) are of the opinion that mothers should have counseling and testing for HIV before they breastfeed, $15.4 \%$ said that if a mother suspect herself of having HIV she should be tested, $5.5 \%$ of them said that mothers must breastfeed regardless of their being tested, $0.5 \%$ said that it is better to abstain breastfeeding whether one is tested or not and $9.4 \%$ did not respond. These results are different from the results obtained in studies conducted in Kenya in which $43 \%$ of mothers in Turkana, $42.4 \%$ in Kwale, $42.8 \%$ in Garissa and $44.8 \%$ in Isiolo thought that all babies should be breastfed irrespective of their mothers' HIV status (11).

In conclusion, all the participants in this study had heard about HIV/AIDS and most of them knew that it could be transmitted from an infected mother to her baby. Almost all of them mentioned at least one period of transmission and nearly half of them mentioned all periods in which mother to child transmission of HIV occurs. Nearly half of them knew one or more factors, which increase the risk of mother to child transmission of HIV. Most of the mothers knew that it is possible to prevent mother to child transmission of HIV and most said that it is by giving prophylactic anti retroviral drugs and some mentioned abstinence of breast feeding but only few of them mentioned the primary prevention i.e. protection of the mother from HIV is protecting the baby against HIV. A majority of the study participants knew about VCT and have the opinion that VCT can be one strategy to prevent MTCT of HIV. Most of the study participants expressed their intention to have counseling and testing for HIV prior to the next pregnancy.

This study is hospital based and has some limitations. The findings of increased awareness and adequate knowledge about MTCT of HIV among mothers in urban settings seem encouraging. But still a considerable percentage of mothers do not have knowledge of MTCT and VCT. This indicates, therefore, the need for exerting more effort to teach mothers about VCT \& PMTCT. As the study participants have the desire to have VCT, it is also prudent to provide and expand VCT and PMTCT centers in most of the healthcare facilities in the city.

\section{Acknowledgement}

We would like to acknowledge the Ethiopian Public Health Association (EPHA) for granting the fund to undertake this study. We are also thankful to Sr. Zenabwa Girmay and Sr. Tsige Kefyalew, both staff nurses of Tikur Anbessa Hospital, who collected the data. We thank Dr. Tadele Bogale and Dr. Senait Afework for their assistance in questionnaire development, data analysis and interpretation. We appreciate the following for their valuable comments on the first draft, Dr. Amha Mekasha, Dr. Berhanu Gudeta, Dr. Ahmed Bedru, (Department of Pediatrics and Child Health) Ato Berhanu Legesse, (EPHA Research and Dissemination Officer), Ato Wakgari Deressa, Dr. Alemayehu Worku, Ato Fikre Enkuselasse and Dr Nigussie Deyessa (Department of Community Health).

We also extend our thanks to Dr Damen H. Mariam for his valuable comments on the final draft of this paper. Special thanks also go to Ato G/Micheal G/Silasse of AIDS Resource Center for his assistance in literature search and W/t Rahel Adamu for providing important information. Finally, we acknowledge all the mothers who have participated in this study.

\section{References}

1. UNAIDS, Report on the Global HIV/ AIDS Epidemic, December 2002.

2. UNAIDS, Report on the National HIV/ AIDS Epidemic, December 2002.

3. McIntyre J, Gray G. What can we do to reduce MTCT of HIV? British Medical Journal 2002; 26 Jan, No. 7331:218-221

4. Working Group Report of AIDS and infectious disease PMP, and mother to child transmission of HIV, Acta Paediatrica 2001; 90: 1337-1339.

5. Lynne M, Munderi M, Paula, Mofenson. Safety of Antiretroviral prophylaxis of perinatal transmission of HIV Infected pregnant women and their children. Journal of AIDS 2002 Jun 1; 30 (2): 200-15.

6. Yogev R and Chadwick E G, Acquired Immune Deficiency Syndrome, Nelson Text Book of Pediatrics, 17th Edition: 1109-1121

7. Im-em $\mathrm{W}$, VanLandingham $\mathrm{M}$, Knoldel $\mathrm{J}$, Saegtienchai C. HIV/AIDS related knowledge and attitudes: A comparison of older persons and young adults in Thailand, AIDS Education and Prevention, 2003, 14 (3): 246-262.

8. Ngare D, Njagi E, Hassan, A, Meme J, Wangai, M, Chebet K, Kimathi J. Community's Knowledge, attitudes and practice on MTCT OF HIV: Challenges 
of PMTCT upscaling in Kenya. HIV/AIDS, STDS and TB, challenges and strategies in combating health problems in Africa, towards development efforts, $24^{\text {th }}$ African Health Sciences Congress Abstracts, Session I :2

9. Sameness D, HIV/AIDS awareness, knowledge and practice in patients with STD. Ethiopian Medical Journal, Jan 1996, vol. 34 no 1, 25-32.

10. Anthon M, Chala F, Sexual behavior and knowledge and attitude towards HIV/AIDS among out-ofschool youth in Bihar Dar Town, northwest Ethiopia. Ethiopian Med Journal, Oct 1994 vol. 34, no 4: 233243.
11. Visconti E, Celentano LP, Marinai S, Scoppettulo G, Tamborrini E. MTCT of HIV: What HIV infected women think. Our experience in Rome, Italy, International Journal of STD, AIDS 200113 (8): 551-3.

12. Negara D, Kamahi J, Meme J, Wanda M, Chi bet K, Nagy E, Hessian A. Upscaling of PMTCT in Kenya: Health workers knowledge, attitudes and practice in four districts. HIV/AIDS, STD and TB, challenges and strategies in combating health problems in Africa, towards development efforts, $24^{\text {th }}$ African Health Sciences Congress Abstracts, Session I: 3. 
